\title{
Edukasi Pendidik Sebaya (peer Group) Kepada Pasien TB Resisten Obat Agar Patuh Menjalani Terapi Pengobatan
}

\author{
Oleh
}

\author{
Ali Wachidin', \\ aliwachidin45@gmail.com \\ Universitas 45 Surabaya
}

\author{
Rio Sigit Baskoro ${ }^{2}$, \\ riosigitbaskoro@univ45sby.ac.id \\ Universitas 45 Surabaya \\ Ani Herna Sari ${ }^{3}$ \\ anihernasari@univ45sby.ac.id \\ Universitas 45 Surabaya
}

\begin{abstract}
Abtract
The world and Indonesia are still experiencing major issues in public health in overcoming Tuberculosis (TBC). In 2018, Indonesia contributed 10\% of the world's burden of 10 million people who fell sick due to tuberculosis. TBC treatment takes a long time 6 months - 24 months depending on the category of TBC. Multy Drug Resistant TBC (TBC RO) with a long treatment period between 9 months - 24 months makes patients decide to stop treatment and this will affect themselves and others considering $T B C$ disease is very easily transmitted through the air. Peer educators are survivors of TBC RO who have humanity to provide education to patients who are undergoing treatment so that they are more enthusiastic about taking medication until they recover. This study used a qualitative method with 10 informants. Research has shown that education provided by peer educators has the effect of getting patients to take medication regularly. They see peer educators as role models who have recovered from a long treatment and with all kinds of side effects.
\end{abstract}

\begin{abstract}
Abstrak
Dunia dan Indonesia sampai saat ini masih mengalami isu besar dalam kesehaan masyarakat untuk menanggulangi penyakit Tuberkulosis (TBC). Tahun 2018, Indonesia berkontribusi sebesar $10 \%$ terhadap beban dunia sebesar 10 juta orang yang jatuh sakit akibat TBC. Pengobatan TBC memakan waktu yang tidak sebentar 6 bulan -24 bulan tergantung kategori TBC yang di derita. TBC Resisten obat (TBC RO) dengan jangka waktu pengobatan yang lama antara 9 bulan- 24 bulan membuat pasien yang memutuskan untuk berhenti berobat dan hal ini akan berakibat terhadap diri sendiri dan orang lain mengingat penyakit TBC penularannya sangat mudah yaitu melalui udara. Pendidik sebaya adalah survivor dari TBC RO yang mempunyai jiwa kemanusiaan untuk memberikan edukasi kepada pasien yang sedang menjalani pengobatan agar mereka lebih semangat untuk minum obat sampai sembuh. Penelitian ini menggunakan metode kualitatif dengan informan sebanyak 10 orang. Penelitian menghasilkan bahwa edukasi yang
\end{abstract}


Dinamika Sosial Budaya, Vol 22, No. 2, Desember 2020, pp 306-313

p-ISSN: 1410-9859\& e-ISSN: 2580-8524

http://journals.usm.ac.id/index.php/idsb

diberikan oleh pendidik sebaya mempunyai pengaruh untuk membuat pasien mau minum obat secara teratur. Mereka melihat pendidik sebaya sebagai role model yang sudah sembuh menjalani penngobatan yang lama dan dengan berbagai macam efek samping.

Kata kunci : Edukasi pendidik sebaya, Tuberkulosis, komunikasi 


\section{LATAR BELAKANG}

Kesehatan sampai saat ini masih menjadi fokus perhatian di tingkat global dimana dalam tujuan Pembangunan berkelanjutan salah satu poinnya menyebutkan bahwa memastikan memastikan kehidupan yang sehat dan mendukung kesejahteraan manusia di segala usia. Adanya komitmen Bersama untuk mengakhiri epidemi pada tahun 2030 seperti AIDS, Tuberkulosis (TBC), malaria dan penyakit tropis lainnya (SDGs dalam United Nations, 2015). Penyakit (desease) adalah suatu kondisi tubuh mengalami reaksi biologis terhadap suatu organisme, benda asing atau luka (Nugraheni, Wiyatini, \& Wiradona, 2018). Salah satu penyakit yang menjadi pemicu tingginya tingkat kematian baik di dunia maupun di Indonesia adalah Tuberculosis (TBC) (Pranita, 2020). TBC di Indonesia masih tergolong tinggi menurut WHO (World Health Organization). Indonesia masih menempati rangking ke-3 dunia setelah Tiongkok dan India (Manafe, 2019). Data WHO tahun 2019 menyebutkan bahwa terdapat peningkatan kasus TBC sebanyak 845.000 kasus (WHO, 2019). Penyakit TBC menular melalui droplet Ketika pasien batuk, bersin dan pada saat berbicara. Bakteri ini TBC ini dapat menular dari manusia ke manusia melalui droplet pasien yang terbawa oleh udara.

Sejumlah program pemerintah untuk menurunkan jumlah kasus TBC sudah tergolong maksimal. Seperti program TOSS TBC yang merupakan singkatan dari Temukan Obati Sampai Sembuh. Namun hal tersebut juga masih belum bisa menekan laju peningkatan penderita TBC, hal ini dikarenakan banyak faktor, antara lain : masih banyak penderita TBC yang masih diobati dan belum sembuh benar, kemudian masih banyak juga angka TB Laten yang mencapai 20 jutaan di Indonesia. TBC laten ini adalah orang yang sudah terinfeksi TBC namun karena mempunyai kekebalan tubuh yang kuat membuat kuman ini dorman atau belum sampai menjadi penyakit (Manafe, 2019). Faktor penghambat lainnya adalah lamanya pengobatan yang membuat pasien jenuh serta adanya efek samping obat (Widuri, 2019). Faktor lain juga antara lain tidak adanya Pengawas Minum Obat (PMO) dan juga keputusan pasien yang menunda ataupun tidak meneruskan pengobatan (Maulidya, Redjeki, \& Fanani, 2017). Semakin lama penderita memutuskan akan menjalani pengobatan atau tidak akan mengakibatkan resiko penularan yang tinggi juga.

Untuk itu dibutuhkan informasi yang tepat kepada pasien agar pada saat pasien menerima penjelasan tentang bagaimana penyakitnya dan berapa lama waktu yang dibutuhkan akan membuat pasien mau menjalani pengobobatan. Dengan mendapatkan informasi yang tepat diharapkan calon pasien mendapatkan pengetahuan yang tepat. TBC sendiri merupakan penyakit menular yang berasal dari bakteri mikrobacterium Tubbercolosis (Sari, 2019). Penularannya sangat mudah dengan media udara. Sehingga jika 1 orang penderita TBC yang tidak di obati maka akan bisa menginfeksi sekita $10-15$ orang per tahunnya (Maharani, 2016). Menurut lamanya pengobatan dan jenis obat yang diminum TBC ini ada perbedaannya pada tabel dibawah ini (Sari, 2019): 
Dinamika Sosial Budaya, Vol 22, No. 2, Desember 2020, pp 306-313

p-ISSN: 1410-9859\& e-ISSN: 2580-8524

http://journals.usm.ac.id/index.php/jdsb

Tabel 1.1. Perbedaan mendasar antara TB regular dan TB Yulty Drug Resistant:

\begin{tabular}{|c|c|c|c|}
\hline & TB Requller. & TB Resisten Obat(TBRO) & $\begin{array}{l}\text { TB Extra Resisteen Obat } \\
\text { (TBRO Elsstra) }\end{array}$ \\
\hline Jenis yang Diminum & $\begin{array}{l}4 \text { jenis oldat bentuts Fixed } \\
\text { Dosed Combination (FDC) }\end{array}$ & 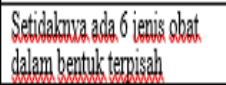 & 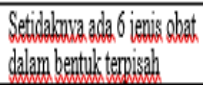 \\
\hline Suntilik & Tidal & $\begin{array}{l}\text { Ya minimal selama } 6 \text { bulan } \\
\text { setiap hari }\end{array}$ & $\begin{array}{l}\text { Ya minimal selama } 6 \text { bulan } \\
\text { setian hari }\end{array}$ \\
\hline Lama pengobatan & 6 bulan & 9.20 bulan & 24 bulan \\
\hline Efelssamping & Relative ringan & $\begin{array}{l}\text { Lebih berat beberapa kasus } \\
\text { pada tuli permanen }\end{array}$ & $\begin{array}{l}\text { Lebih berat beberana lassls } \\
\text { pada jantung dan tuli } \\
\text { permanen }\end{array}$ \\
\hline $\begin{array}{l}\text { Cara pengambilan } \\
\text { Obat }\end{array}$ & $\begin{array}{l}\text { Di Frasilitas kesechatan dan } \\
\text { boleh dibariva pulang }\end{array}$ & 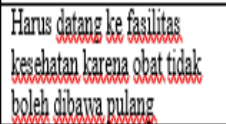 & $\begin{array}{l}\text { Harus datang ke fasilitas } \\
\text { kesehantan karena obat tidak } \\
\text { boleh dibariva pulang }\end{array}$ \\
\hline Harga Obat & Gratis & Gratis & Gratis \\
\hline
\end{tabular}

Sumber : kncv.orid

Pada tabel diatas dpat diketahui bahwa untuk TB Reguler mendapatkan pengobatan selama 6 bulan sedangkan untuk TB Resisten Obat dan TB Ekstra Resisten Obat mendapatnya pengobatan antara $9-24$ Bulan tergantung pada kondisi pasien saat memulai pengobatan. Pada tabel diatas juga bisa diketahui bahwa efek samping obat lebih berat dan juga ada yang permanen untuk kasus efek samping pada pendengaran. Hal ini lah yang menurut penulis patut mendapat perhatian lebih. Pada pasien TB Resisten Obat memiliki angka lost to follow up (LFU) lumayan tinggi karena jangka waktu pengobatan yang lebih lama dan juga efek samping obat. Pada tabel Tabel 2 di bawah menjelaskan tentang 5 Provinsi dengan beban kasus TBC terbanyak (Sari, 2019)
Tabel 2 : Lima Propinsi dengan Beban TBC terbanyak

\begin{tabular}{|l|r|r|r|r|}
\hline \multicolumn{1}{|c|}{ Provinsi } & Kasus TBRO & Diobati & $\begin{array}{c}\text { Tidak/Belum } \\
\text { Berobat }\end{array}$ & $\begin{array}{c}\text { LFU } \\
\text { Pengobatan }\end{array}$ \\
\hline JAWA BARAT & 1,942 & 751 & 1,191 & 82 \\
\hline JAWA TIMUR & 1,360 & 559 & 801 & 110 \\
\hline DKI JAKARTA & 1,222 & 644 & 578 & 76 \\
\hline JAWA TENGAH & 788 & 462 & 326 & 64 \\
\hline SUMATERA UTARA & 540 & 351 & 189 & 57 \\
\hline "* LFU = Lost To Follow Up \\
* Sumber : Data Kementrian Kesehatan 2018 \\
\hline
\end{tabular}

Berbagai cara telah dilakukan untuk menanggulangi TC di Indonesia, salah satu diantaranya adalah keterlibatan semua stakeholder TBC yang saling bekerja sama untuk keberhasilan program eliminasi TBC di Indonesia. Penderita TBC perlu diberikan pengetahuan yang dibutuhkan agar bisa mendorong mereka secara psikis untuk menumbuhkan rasa percaya bahwa penyakit yang di derita bisa disembuhkan. Dengan menumbuhkan rasa percaya diri bagi penderita TBC diharapkan akan memberikan motovasi kepada diri penderita untuk mau menjalani terapi pengobatan sampai sembuh.

Kelompok sebaya (peer educator) adalah kumpulan dari pasien TBC yang sudah selesai menjalani pengobatan untuk kemudian memiliki kepedulian yang tinggi terhadap pasien TBC yang masih menjalani pengobatan agar mau mengikuti jejak mereka. Kelompok sebaya merupakan role model bagi pasien yang masih menjalani pengobatan. Mereka adalah contoh sukses yang bisa membagikan pengalaman mereka selama menjalani masa terapi pengobatan.

Pada penelitian kali ini, penulis mewawancara 10 narasumber yang berada di beberapa puskesmas yang berada di wilayah Surabaya. Penulis ingin menggali lebih dalam bagaimana edukasi yang dilakukan oleh kelompok sebaya agar pasien mau dan masih tetap bersemangat dalam menjalani pengobatan? 


\section{TUJUAN :}

Tujuan penelitian ini adalah untuk mengetahui bagaimana edukasi yang dilakukan oleh kelompok sebaya agar pasien yang masih dalam pengobatan tetap bersemangat dalam menjalani hari-hari terapi pengobatan.

\section{METODE :}

Penelitian ini menggunakan metode kualitatif dengan pengambilan data melalui observasi partisipatif, wawancara mendalam. Dimana menurut Moleong metode penelitian kuliatatif ini merupakan suatu metode penelitian ilmiah yang mempunyai tujuan untuk memahami fenomena dalam konteks yang secara sosial mengedepankan proses interaksi dalam berkomunikasi antara peneliti dengan fenomena yang diteliti (Herdiansyah, 2010). Dalam penelitian ini menggunakan jenis penelitian deskriptif yang berupaya untuk menggambarkan situasi, kondisi, gejala maupun hubungan yang akan dapat menggambarkan subyek secara mendetail. (Neuman,2006). Sampel diambil dengan metode snow ball sampling. Data yang di dapatkan kemudian dianalisis dengan menggunakan keabsahan data yang bertujuan untuk mengetahui bagaimana edukasi yang dilakukan oleh pendidik sebaya.

\section{PEMBAHASAN}

Sehat menurut WHO (1948) adalah keadaan seseorang dimana fisiknya, kemudian mental dan sosial dalam kondisi yang sempurna dan bukan hanya sekedar tidak sakit atau tidak cacat (Nugraheni et al., 2018). Pasien TBC merupakan populasi dengan resiko tinggi dan rentan mengalami stigma dan diskriminasi. Hal ini dikarenakan karena masyarakat banyak yang belum paham apa dan bagaimana cara penularan TBC. Masyarakat awam umumnya hanya mengetahui bahwa penyakit TBC itu menular. Dan stigma yang terjadi dimasyarakat adalah penderita TBC dikucilkan karena mereka takut untuk tertular.

Salah satu bentuk untuk menanggulangi penyakit TBC adalah adanya bentuk intervensi keperawatan komunitas pada pesien TB Resisten Obat. Intervensi melalui komunitas ini dalam bentuk peer education (Edukasi sebaya). Edukasi sebaya adalah salah satu dari bentuk kegiatan dengan memberikan informasi Kesehatan dengan pendekatan sebaya. Kelompok sebaya melakukan edukasi kepada pasien sebagai bentuk dari pemberdayaan individu untuk mendukung keberhasilan program untuk dapat mempratikkan pola hidup sehat seharihari (Pender, et All, 2002). Penelitian senada juga pernah dilakukan hasil bahwa aktifitas yang dilakukan oleh kelompok sebaya dapat memberikan dampak positif (Yansyah, 2011). Berdasarkan dari hasil wawancara secara mendalam kepada 10 orang penderita TB Resisten Obat yang terdiri dari 6 Perempuan dan 4 Laki-laki. Terdapat kesamaan pandangan mereka mengenai pendidik sebaya, yaitu :

1. Perasaan terbantu saat ada kesulitan : berdasarkan penjelasan dari informan mereka merasa lebih nyaman saat bercerita tentang kesulitan yang dialami selama masa pengobatan. Pada tahapan ini pendidik sebaya juga memberikan konseling terkait permaslaahan yang dihadapi. Dalam proses konseling ini terjadi hubungan timbal balik yaitu saling bantu membantu dan bekerja sama untuk menyelesaikan masalah tertentu agar pasien bisa lebih dapat menyesuaikan diri (Depkes RI, 2010). Hal ini dikarena 
masa pengobatan yang lama memang menjadi salah satu kendala terbesar dalam terapi pengobatan TBC. Informan yang diwawancara juga salah satu dari sekian banyak pasien yang harus berhenti dari pekerjaannya karena tidak bisa fokus bekerja saat efek samping obat bekerja.

2. Saat ada permasalahan mengenai efek samping bisa saling berbagi : Meskipun bukan dokter namun pendidik sebaya mempunyai kelebihan yang memang dokter tidak punya yaitu pengalaman pernah ada di posisi yang sama dengan pasien saat ini. Pendidik sebaya juga pernah merasakan sakit dan capek nya harus di suntik setiap hari selama minimal 6 bulan. Pendidik sebaya juga pernah merasakan mual hebat karena efek samping obat. Pengalaman ini membuat pasien merasa memiliki keterikatan emosional karena sama sama pernah berasa diposisi yang sama. Penelitian lain juga menunjukkan bahwa terdapat pengaruh yang signifikan setelah pendidik sebaya memberikan edukasi nya selama 3 kali pertemuan. Hasil penelitian menunjukkan bahwa terdapat peningkatan pengetahuan dengan adanya edukasi dari pendidik sebaya (Nisma, 2008).

3. Merasa nyaman saat berkonsultasi dengan pendidik sebaya dibandingkan dengan dokter. Hal ini berhubungan dengan seni berkomunikasi yang efektif dimana pendidik sebaya mampu membuat pasien merasa nyaman saat mereka mengatakan tentang keluh kesahnya. Komunikasi bisa berwujudverbal maupun non verbal seperti tatapan mata ketika berbicara, dan juga tatapan mata Ketika harus mendengarkan. Dengan komunikasi antara pendidik sebaya dan juga pasien bisa saling bertukar pesan, sehingga dapat terbangun interaksi positif (Sasongko, 2016), serta dapat menumbuhkan kepercayaan terhadap pasien sehingga terjalin kedekatan (Suryadinata, 20016). Dalam Gillies (2000) Komunikasi yang efektif juga bisa meminimalkan kesalahpahaman, dapat memberikan pandangan positif,(Marquis dan Huston, 2006).

4. Bisa dan mau menampung keluh kesah pasien meskipun tidak ada hubungan dengan pengobatan. Pada pasien yang sudah menjalani pengobatan umumnya mengalami stress yang termanifestasi baik secara fisik dan psikologis. Seseorang dengan Penyakit TB dapat membatasi mereka secara fisik, sosial maupun emosional. Keterbatsaan itu terkadang menyebabkan ketidakberdayaan atau perasaan tidak berguna. Hambatan menuju kesembuhan terkait dengan proses pengobatan sering dikaitkan dengan gangguan kejiwaan . Hal ini terjadi karena kondisi yang dialaminya, seperti proses pengobatan yang lama dan dengan jumlah obat yang banyak, efek samping obat sehingga dapat mengganggu aktivitas sehari-hari. Hal ini dapat mengakibatkan ancaman kematian. kondisi stress ini dapat mengakibatkan pasien TBC tidak teratur minum obat bahkan bisa sampai putus berobat yang berakibat pada turunnya kualitas hidup (Nihayati, 2019). Sebagai pendidik sebaya juga harus mampu menampung keluh kesah pasien, meskipun bukan ahli psikologi namun pengalaman mereka saat berada di posisi yang sama dengan pasien saat ini membuat pendidik sebaya paham keadaan psikologis yang dialami pasien. Pasien yang didampingi akan merasakan perasaan tidak sendirian dan 
dapat merasa bahwa mereka mendapat perhatian dari pendidik sebaya (Faizah et al., 2016).

\section{KESIMPULAN}

Informasi tentang bagaimana dapat menjalani terapi pengobatan dengan minum obat secara teratur dapat diperoleh dari teman sebaya atau peer group. Pendidikan yang dapat dilakukan oleh kelompok sebaya (peer education) adalah dengan melalui proses komunikasi, informasi dan edukasi (KIE) yang dilakukan oleh dan untuk kalangan sebaya. Edukasi yang dilakukan oleh peer group merupakan upaya perubahan perilaku melalui kelompok sebaya yang menekankan pada perubahan perilaku Pada metode ini terjadi interaksi dalam kelompok, individu akan merasa ada kesamaan satu dengan lain, dan individu akan mengembangkan rasa sosial sesuai dengan perkembangan kepribadian.

Pada penelitian ini tidak mempertimbangkan tentang jenis kelamin dan usia yang bisa dijadikan pertimbangan untuk penelitian selanjutnya. Bahwa edukasi pendidik sebaya kepada pasien TBC adalah penting untuk mendukung kepatuhan pasien minum obat setiap hari. Pendidik sebaya juga di tuntut untuk bisa berkomunikasi secara efektif agar pesan yang ingin di sampaikan bisa tersampaikan.

\section{DAFTAR PUSTAKA}

Depkes RI. (2010). Pedoman

Penanggulangan HIV \& AIDS. Jakarta: Depertemen Kesehatan RI

Faizah, U. et al. (2016) 'Gangguan psikiatri pasien TB-MDR (Multi Drug Resistant) dan stres psikososial yang memengaruhi di RSUP Persahabatan', Journal of The Indonesian Medical
Association, 66(10), pp. 473-480.

Available at:

http://mki.idionline.org/index.php?uPa ge=mki.mki $\mathrm{dl} \& \mathrm{smod}=\mathrm{mki} \& \mathrm{sp}=$ publi c\&key=NDMOLTEy.

(Informasi TBC $\mid$ Forum Stop TB

Partnership Indonesia, 2018)

Herdiansyah, Haris. Metode Penelitian Kualitatif untuk Ilmu-ilmu Sosial. Jakarta: Salemba Humanika, 2010

Maharani, D. (2016). Patuh Minum Obat, Tuberkulosis Bisa Disembuhkan! Retrieved June 20, 2020, from https://sains.kompas.com/read/2016/03/ 24/091500423/Patuh.Minum.Obat.Tub erkulosis.Bisa.Disembuhkan.

Manafe, D. (2019). Indonesia Peringkat Ke3 Kasus TB Tertinggi Dunia BeritaSatu.com. Retrieved June 19, 2020, from https://www.beritasatu.com/kesehatan/ 590064-indonesia-peringkat-ke3-kasustb-tertinggi-dunia

Maulidya, Y. N., Redjeki, E. S., \& Fanani, E. (2017). Faktor Yang Mempengaruhi Keberhasilan Pengobatan Tuberkulosis (Tb) Paru Pada Pasien Pasca Pengobatan Di Puskesmas Dinoyo Kota Malang. Preventia: The Indonesian Journal of Public Health, 2(1), 44. https://doi.org/10.17977/um044v2i1p44 $-57$

Marquis, B.L\& Houston C.J (2010) Kepemimpinan dan Manajemen Keperawatan Teori dan Aplikasi. Jakarta : EGC

Nihayati, D. H. E. (2019) Tingkat Stress Pasien Tuberkulosis Paru Setelah Dilakukan Intervensi Psikoreligi Unair News. Available at: http://news.unair.ac.id/2019/12/06/ting 
kat-stress-pasien-tuberkulosis-parusetelah-dilakukan-intervensipsikoreligi/ (Accessed: 24 August 2020).

Nisma (2008). Pengaruh Penyampaian

Pendidikan Kesehatan Reproduksi oleh Kelompok Sebaya (Peer Group) Terhadap Pengetahuan Kesehatan Reproduksi Remaja di SMP N 2 Bantul Yogyakarta. Tesis Muhammadiyah Yogyakarta

Nugraheni, H., Wiyatini, T., \& Wiradona, I. (2018). Kesehatan Masyarakat dalam Determinan Sosial Budaya (cetakan pe). Retrieved from https://books.google.co.id/books?id=zW CKDwAAQBAJ\&pg=PA133\&lpg=PA $133 \& d q=$ Penyakit + adalah + suatu + bentu $\mathrm{k}+$ reaksi+biologis+terhadap+suatu+org anisme,++benda+asing+atau+luka\&sou rce $=$ bl\&ots $=$ ZTALVq4bIw\&sig $=$ ACfU 3U11nRNYHe54n9Xu-

TAsVdY7gSy8Wg\&hl=en\&sa=X\&ved $=2$ ahUKEwipjd

Pender, N. J., Murdaugh, C. L., \& Parsons, M. A. (2002). Health promotion in nursingpractice (4th ed.). Upper Saddle River, NJ: Prentice Hall

Pranita, E. (2020). TBC Penyakit Menular Berbahaya, Kenali Gejala hingga Pencegahannya. Retrieved June 20, 2020, from https://sains.kompas.com/read/2020/02/ 04/073200223/tbc-penyakit-menularberbahaya-kenali-gejala-hinggapencegahannya?page $=$ all

Sari, A. H. (2019). Kolaborasi Stakeholder Menuju Indonesia Bebas TB 2050 (Studi Kasus tentang penanganan TB Resisten Obat DI RSUD dr. Soetomo Surabaya). Jurnal Teknik Industri, 22(01). Retrieved from http://univ45sby.ac.id/jurnal/index.php/ industri/article/view/263

Sasongko, A. (2016). Jagalah quality time keluarga Anda. Republika.co.id.

Ditemu kembali dari http://gayahidup.republika.co.id/berita/ gayahidup/parenting/16/08/20/oc71fa313jagalahquality-time-keluarga-anda

Suryadinata, E. (2016). Proses komunikasi interpersonal antara orang tua tunggal (ibu) dengan anak dalam mempertahankan intimacy. Jurnal EKomunikasi, 4(1), 1-10

WHO. (2019). Global Tuberculosis Report 2019. In World Health organozation 2019. Geneva.

Widuri, T. S. (2019). Durasi Fase Kuratif Jadi Kendala Utama Masalah Resisten Tuberkulosis Tak Kunjung Tuntas Unair News. Retrieved June 19, 2020, from Uniar News website: http://news.unair.ac.id/2019/04/08/dur asi-fase-kuratif-jadi-kendala-utamamasalah-resisten-tb-tak-kunjungtuntas/

Yansah, F. (2011). Peran Peer Educator Remaja Dalam Pemberian Informasi Kesehatan Reproduksi Remaja (Studi Pada PKBI Lampung). FISIP, from http://

repository.unila.ac.id:8180/dspace/han dle/ 123456789/2953?mode=full 